\title{
A Continuum Damage Model for the Stress Corrosion Cracking of Austenitic Stainless Steel
}

\author{
and J. F. V. Vasconcellos \\ Instituto Politécnico \\ Universidade do Estado do Rio de Janeiro \\ Caixa Postal 97282 \\ 28601-970 Nova Friburgo, RJ. Brazil \\ inbastos@iprj.uerj.br
}

J. A. C. P. Gomes

PEMM/COPPE

Universidade Federal do Rio de Janeiro

llha do Fundão

21945-970 Rio de Janeiro, RJ. Brazil

\section{H. S. da Costa-Mattos}

Laboratório de Mecânica Teórica e Aplicada Departamento de Engenharia Mecânica

Universidade Federal Fluminense 24210-240 Niterói, RJ. Brazil
In the present work, the mechanical behavior of stress corrosion cracking phenomenon is described. Such phenomenon presents strong complexity due to metallurgic and electrochemical aspects. A methodology for modeling both SSR (Slow Strain Rate) and CL (Constant Load) tests based upon thermodynamics of continuum solids and elastoplastic damage is proposed. In this macroscopic approach, besides the classical variables (stress, total strain, plastic strain), an additional scalar variable related to the damage induced by stress corrosion is introduced. An evolution law depending on the corrosive environment parameters is proposed for this damage variable. The model accounts for the stress corrosion effect through a reduction of the mechanical resistance of the material induced by the damage variable. The model prediction is compared with the curves obtained experimentally in different acid solutions at room temperature showing a good agreement. The alloy/environment system studied here is an AISI 304 austenitic stainless steel in acid aqueous solution containing sodium chloride.

Keywords: Slow strain rate test, constant load test, damage mechanics, stress corrosion cracking, stainless steel

\section{Introduction}

Stress corrosion cracking (SCC) remains as one of the most severe limitations for the use of austenitic stainless steels on chemical and petrochemical industries. The combined effect of corrosion and mechanical stress imposed on the material is extremely complex. The mechanisms proposed to explain microscopically the cracking initiation and propagation processes are not able to elucidate all aspects of this phenomenon in different metal/environment systems (Newman, 1995). Therefore attempts to predict this phenomenon in macroscopic scale models are advisable.

Slow strain rate and constant load tests are widely used on stress corrosion cracking research as the basic experimental technique to promote the incidence of cracking and to determine the ranking of susceptibility of different alloys in several corrosive environments. With this methodology, however, the assessment of "threshold values" to be used as design parameters is not a simple task in the present state of the art of materials research. This limitation induces the use of the SSR and CL testing only as "go-no go" test for material selection. Some basic information is required, such as the time to failure in service, which cannot be inferred from this procedure. The most important reason for this limitation is the complexity of stress corrosion mechanism, which involves the conjoint action of mechanical and electrochemical processes (Bastos et al., 2005).

Despite the lack of definition of a fundamental mechanism for stress corrosion cracking, the evaluation of the susceptibility to cracking is a basic requirement for safe and economical operation of many types of equipments. This objective is accomplished by the execution of a set of laboratory tests that simulates the conditions of SCC incidence. In this situation, slow strain rate testing is the most important technique used to rank the susceptibility of different materials in a specific environment (Nishimura and Maeda, 2004). Constant load and constant displacement tests are frequently used as auxiliary techniques in order to obtain more detailed information

Paper accepted May, 2005. Technical Editor: Atila P. Silva Freire. about the resistance of the material. These tests, however, do not provide basic parameters to be directly used in engineering design or to determine the "safe life" of equipment. This limitation can be explained as a consequence of the nonexistence of a model to interpret the macroscopic behavior of the material observed during the SCC tests.

The most interesting possibilities of macroscopic modeling of stress corrosion testing are provided by fracture mechanics and continuum damage mechanics. In the case of continuum damage mechanics, the damage is taken into account through an internal variable related to the loss of mechanical strength of the system due to the damage (geometrical discontinuities induced by the deformation process). Besides, this approach introduces the possibility of considering important physical phenomena like hardening, plasticity, viscoplasticity and corrosion. Despite the technological importance of stress corrosion cracking to industry, just few research works have been published (Garud, 1990; Santarini, 1989; Nishimura and Maeda, 2003).

In this paper the mechanical behavior of stress corrosion cracking of an AISI 304 stainless steel in acidic media at room temperature is simulated based on continuum damage mechanics and the simulations are compared with experimental results.

\section{Nomenclature}

$S S R=$ slow strain rate
$C L=$ constant load
$D=$ damage $($ related to the loss of mechanical strength)
$L_{0}=$ gauge length
$A_{0}=$ cross-section
$\sigma=$ stress
$\sigma_{p}=$ yield stress
$Y=$ elastic limit
$\varepsilon=$ deformation
$\varepsilon_{p}=$ plastic deformation
$E=$ elastic modulus
$K=$ coefficient of plastic resistance
$N=$ viscosity exponent
$v_{l}=$ hardening coefficient


$v_{2}=$ hardening coefficient

$\eta=$ plastic damage coefficient

$S=$ parameter dependent on the material and environmental conditions

$R=$ parameter dependent on the material and environmental conditions

$t=$ time

$a=$ plastic damage coefficient

$\beta$-parameter

\section{Subscripts}

$p$ relative to plasticity

$e$ relative to elasticity

$r$ relative to rupture

$C R$ relative to critical value

${ }_{0}$ relative to initial conditions

\section{Experimental Procedures}

Slow strain rate (SSR) and constant load (CL) tests were performed at different acid environments with chloride ions. In these tests it was used an AISI 304 stainless steel with the chemical composition given in Table 1.

Table 1. Composition of AISI 304 austenitic stainless steel (wt\%).

\begin{tabular}{|c|c|c|c|c|}
\hline Element & $\mathrm{C}$ & $\mathrm{S}$ & $\mathrm{Ni}$ & $\overline{\mathrm{Si}}$ \\
\hline Wt \% & 0.06 & 0.005 & 8.03 & 0.47 \\
\hline Element & Mo & $\mathrm{Mn}$ & $\mathrm{Cr}$ & $\mathrm{Fe}$ \\
\hline Wt \% & 0.03 & 1.40 & 18.95 & Bal. \\
\hline
\end{tabular}

The steel was previously normalized at $1050^{\circ} \mathrm{C}$ for 30 minutes in argon atmosphere furnace and water-quenched. The surface of the samples was ground to grit 600 with emery paper. After surface preparation, the samples were washed with distilled water and alcohol, and dried with hot air. The round specimens were designed according to ASTM E-8 standard with $4[\mathrm{~mm}]$ nominal diameter and $16[\mathrm{~mm}]$ gauge length. The samples were loaded with 1.5 yield stress in the constant load testing and the strain rate used on slow strain rate testing was $3 \times 10^{-6}\left[\mathrm{~s}^{-1}\right]$. The aerated solutions were prepared from $1 \mathrm{M}$ sodium chloride acidified with $1 \mathrm{M}$ chloride acid to adjust the $\mathrm{pH}$. All the measurements were performed at room temperature under free corrosion potential.

\section{Theoretical Modeling}

In this paper, in order to provide a better understanding of the results from slow strain rate test and constant load test a theoretical analysis is performed, developed within the framework of continuum damage mechanics (Lemaitre and Chaboche, 1990). All the proposed equations can be developed from thermodynamic fundamentals that are not presented here for sake of brevity. A more detailed discussion may be found elsewhere (Bastos, 1999; Bastos et al., 1998; Vera Jr., 2002).

Consider as a system a bar-type tension specimen with gauge length $\mathrm{L}_{0}$ and cross-section $\mathrm{A}_{0}$ submitted to a prescribed displacement. The basic idea is to introduce a macroscopic variable $\mathrm{D} \in|0,1|$, related to the loss of mechanical strength of the system due to the damage (geometrical discontinuities induced by mechanical deformation and the simultaneous corrosion processes). If $\mathrm{D}=0$, the bar is considered "virgin" and if $\mathrm{D}=1$, it is "broken" (it can no longer resist to mechanical loading). The following model is proposed to describe the coupling between elastoplasticity and the damage induced by the stress corrosion phenomenon:

$$
\begin{gathered}
\sigma=(1-\mathrm{D}) \mathrm{E}\left(\varepsilon-\varepsilon_{\mathrm{p}}\right) \\
\mathrm{Y}=(1-\mathrm{D})\left[\mathrm{v}_{1}\left(1-\mathrm{e}^{-\mathrm{v}_{2} \varepsilon_{\mathrm{p}}}\right)+\sigma_{\mathrm{p}}\right] \\
\frac{\mathrm{d} \varepsilon_{\mathrm{p}}}{\mathrm{dt}}=\left\langle\frac{\sigma-\mathrm{Y}}{\mathrm{K}}\right\rangle^{\mathrm{N}} \\
\frac{\mathrm{dD}}{\mathrm{dt}}=\frac{\eta \sigma^{2}}{\mathrm{E}(1-\mathrm{D})^{\mathrm{a}}}\left(\dot{\varepsilon}_{\mathrm{p}}\right)+\left(\frac{\mathrm{S} \sigma}{1-\mathrm{D}}\right)^{\mathrm{R}}
\end{gathered}
$$

where $\langle x\rangle=\max (0, x)$ and the variables $\sigma, \varepsilon, \varepsilon_{\mathrm{p}}$ are defined as follows

$$
\sigma=\frac{\mathrm{F}}{\mathrm{A}} ; \varepsilon=\frac{\Delta \mathrm{L}}{\mathrm{L}_{0}} ; \varepsilon_{\mathrm{p}}=\frac{\Delta \mathrm{L}_{\mathrm{p}}}{\mathrm{L}_{0}} \text { and } \Delta \mathrm{L}=\Delta \mathrm{L}_{\mathrm{p}}+\Delta \mathrm{L}_{\mathrm{e}}
$$

with $\Delta \mathrm{L}_{\mathrm{e}}$ being the elastic or reversible part of $\Delta \mathrm{L}$ and $\Delta \mathrm{L}_{\mathrm{p}}$ the plastic or irreversible parcel of $\Delta \mathrm{L}$. These variables may be related, respectively, with the nominal axial stress, the axial strain and the axial plastic strain while the system is submitted to a uniaxial stress state. In the presence of macro cracks the actual state of stress is no longer uniaxial and the variables $\sigma, \varepsilon, \varepsilon_{\mathrm{p}}$, must be interpreted as global parameters. $\mathrm{Y}$ is an auxiliary variable related to the hardening induced by plastic deformation. E, K, N, $\mathrm{v}_{1}, \mathrm{v}_{2}, \sigma_{\mathrm{p}}, \eta$ and a are material constants. $\mathrm{S}$ and $\mathrm{R}$ are parameters, which depend on the material and environmental conditions. Equations (1) and (2) will be called the state laws and Eq.(3) and (4) the evolution laws. Normally the evolution laws are used considering a "virgin" initial state: $\varepsilon_{\mathrm{p}}(\mathrm{t}=0)=0$ and $\mathrm{D}(\mathrm{t}=0)=0$. From Eq. (2) and (3) we have:

$$
\begin{gathered}
\frac{\mathrm{d} \varepsilon_{\mathrm{p}}}{\mathrm{dt}}=0, \text { if } \sigma \leq \mathrm{Y} \\
\sigma=(1-\mathrm{D})\left[\mathrm{v}_{1}\left(1-\mathrm{e}^{-\mathrm{v}_{2} \varepsilon_{\mathrm{p}}}\right)+\sigma_{\mathrm{p}}\right]+\mathrm{K}\left(\frac{\mathrm{d} \varepsilon_{\mathrm{p}}}{\mathrm{dt}}\right)^{1 / \mathrm{N}}, \text { if } \sigma>\mathrm{Y}
\end{gathered}
$$

The variable $\mathrm{Y}$ is the elastic limit, which is affected by the plasticity phenomenon (that causes an increasing of the elastic limit $\frac{\mathrm{dD}}{\mathrm{d} \varepsilon_{\mathrm{p}}} \geq 0 \forall \mathrm{D}[0,1], \forall \varepsilon_{\mathrm{p}} \geq 0$ and by the damage (that causes a decreasing of the elastic limit $\left.\frac{\mathrm{dY}}{\mathrm{dD}} \leq 0 \forall \mathrm{D}[0,1], \forall \varepsilon_{\mathrm{p}} \geq 0\right)$. Equation (7) with $\mathrm{D}=0$ is a classical expression for elasto-viscoplastic materials (Lemaitre and Chaboche, 1990). The experimental identification of the parameters $\mathrm{K}, \mathrm{N}, \mathrm{v}_{1}, \mathrm{v}_{2}$ and $\sigma_{\mathrm{p}}$ is reasonably simple and it is described in this reference. The parcel $\left[v_{1}\left(1-e^{-v_{2} \varepsilon_{p}}\right)+\sigma_{p}\right]$ models the non-linear relationship between the elastic limit $Y$ and the plastic deformation $\varepsilon_{\mathrm{p}}$. This expression is verified experimentally and is found in literature (Chimisso, 1994).

The term in Eq. (7) is related to the viscosity-hardening and is responsible for the dependency of the elastic limit on the rate of plastic deformation. The constant $\sigma_{\mathrm{p}}$ corresponds to the elastic limit when the strain rate is very small $\left(\varepsilon_{\mathrm{p}} \rightarrow 0\right)$.

The variable $\mathrm{D}$ is related to the reduction of the free energy of the mechanical system due to the damage induced by the deformation process and corrosion. From Eq. (2), it is simple to verify that $\mathrm{Y} \rightarrow 0$ when $\mathrm{D} \rightarrow 1$. It is also possible to verify from Eq. 
(7) that $\sigma \rightarrow 0$ when $\mathrm{D} \rightarrow 1$. The evolution law Eq. (4) for the damage variable may be divided in two parts: one related to the plastic deformation and other related to the stress corrosion cracking.

$$
\frac{\mathrm{dD}}{\mathrm{dt}}=\underbrace{\frac{\eta \sigma^{2}}{\mathrm{E}(1-\mathrm{D})^{\mathrm{a}}}\left(\dot{\varepsilon}_{\mathrm{p}}\right)}_{\text {plasticity }}+\underbrace{\left(\frac{\mathrm{S} \sigma}{(1-\mathrm{D})}\right)^{\mathrm{R}}}_{\text {stress corrosion }}
$$

The first parcel is the plastic damage and the second corresponds to the corrosion damage. If the rate of plastic deformation is equal to zero, there is no change in the plastic damage.

$$
\dot{\mathrm{D}}_{\text {plast }}=\frac{\eta \sigma^{2}}{\mathrm{E}(1-\mathrm{D})^{\mathrm{a}}}\left(\dot{\varepsilon}_{\mathrm{p}}\right)=0
$$

Supposing that the plastic damage is negligible in a constant load test $\left(\sigma=\sigma_{\mathrm{p}}=\right.$ constant), it is possible to find the analytical solution of the differential equation that governs the damage evolution

$$
\frac{\mathrm{dD}}{\mathrm{dt}}=\dot{\mathrm{D}}_{\text {corr }}=\left(\frac{\mathrm{S} \sigma_{0}}{(1-\mathrm{D})}\right)^{\mathrm{R}} \text { with } \mathrm{D}(\mathrm{t}=0)=0
$$

The solution of the Eq.(10) is

$$
\mathrm{D}(\mathrm{t})=1-\left[1-\left(\mathrm{t}(\mathrm{R}+1)\left(\mathrm{S} \sigma_{0}\right)^{\mathrm{R}}\right]^{\frac{1}{\mathrm{R}+1}}\right.
$$

Since rupture occurs when $\mathrm{D}=1$, it is possible to compute the time $t_{R}$ until the rupture

$$
\mathrm{D}=1-\left(1-\frac{\mathrm{t}}{\mathrm{t}_{\mathrm{r}}}\right)^{\frac{1}{(\mathrm{R}+1)}} \text { with } \mathrm{t}_{\mathrm{r}}=\frac{1}{\mathrm{R}+1}\left(\mathrm{~S} \sigma_{\mathrm{o}}\right)^{-\mathrm{R}}
$$

The evolution law for the stress corrosion damage would be similar to the creep damage law proposed by Kachanov (1986).

From the equations proposed here it is possible to observe that during the slow strain rate tests the damage variable increases smoothly until almost the end of the test $\left(t=t_{R}\right)$ when it increases very fast until rupture $(D=1)$, as it is shown in Figure 1 .

If this kind of damage behavior is observed, it is usual to consider a critical value $D_{c r}$ of the damage variable, beyond which the evolution to the value toward $D=1$ is so fast that it can be considered instantaneous. If, in a conservative approach, the failure is considered to occur when $\mathrm{D}=\mathrm{D}_{\mathrm{cr}}$, the following expression is obtained

$$
\mathrm{D}=1-\left[1-\frac{\mathrm{t}}{\mathrm{t}_{\mathrm{cr}}+\frac{\left(1+\mathrm{D}_{\mathrm{cr}}\right)^{\mathrm{R}+1}}{\mathrm{R}+1}\left(\mathrm{~S} \sigma_{\mathrm{o}}\right)^{-\mathrm{R}}}\right]^{\frac{1}{\mathrm{R}+1}}
$$

with

$$
\mathrm{t}_{\mathrm{cr}}=\frac{1-\left(1-\mathrm{D}_{\mathrm{cr}}\right)^{\mathrm{R}+1}}{\mathrm{R}+1}\left(\mathrm{~S} \sigma_{\mathrm{o}}\right)^{-\mathrm{R}}
$$

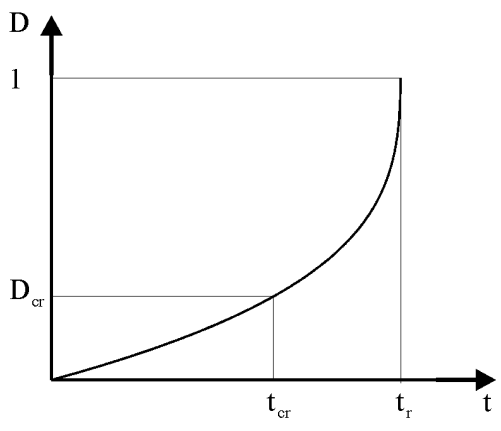

Figure 1. Schematic stress corrosion damage evolution in a slow strain rate test.

From Eq. (12) or (13), the curves of the damage evolution for constant load tests under different conditions may be obtained. Examples of these curves are shown in the next section. It is important to remark that the parameters $\mathrm{R}$ and $\mathrm{S}$ are not independent and are related to $t_{\text {cr }}$ through Eq. (13). The experimental determination of the parameters $\mathrm{R}$ and $\mathrm{S}$ for a given $\mathrm{pH}$ is possible from a unique slow strain rate test and one constant load test and from a single constant load test the value of $t_{c r}$ is obtained. Since $\sigma_{0}$ and $\mathrm{t}$ are fixed, the parameters $\mathrm{R}$ and $\mathrm{S}$ will be related through Eq. (13). Hence, it is only necessary to identify the value of $\mathrm{R}$ in a tensile test.

To understand how the model describes the evolution of the deformation in a constant load test $\left(\sigma=\sigma_{\mathrm{p}}=\right.$ constant $)$, it is necessary to derive Eq. (1).

$$
\begin{aligned}
& \sigma=(1-\mathrm{D}) \mathrm{E}\left(\varepsilon-\varepsilon_{\mathrm{p}}\right) \\
& \Rightarrow \dot{\sigma}=(1-\mathrm{D}) \mathrm{E}\left(\dot{\varepsilon}-\dot{\varepsilon}_{\mathrm{p}}\right)-\dot{\mathrm{D} E}\left(\varepsilon-\varepsilon_{\mathrm{p}}\right) \\
& \Rightarrow \dot{\varepsilon}=\frac{\dot{\sigma}}{(1-\mathrm{D}) \mathrm{E}}+\frac{\sigma \dot{\mathrm{D}}}{(1-\mathrm{D})^{2} \mathrm{E}}+\dot{\varepsilon}_{\mathrm{p}}
\end{aligned}
$$

Since $\sigma$ is a constant and hence $\dot{\sigma}=0$, it comes that

$$
\dot{\varepsilon}=\frac{\sigma \dot{\mathrm{D}}}{(1-\mathrm{D})^{2} \mathrm{E}}+\dot{\varepsilon}_{\mathrm{p}}
$$

As it is shown in the next section, the corrosion elongation curve is fully described by this model. In this model, important parameters, such as steady state elongation rate, and time to failure are also take into account.

\section{Comparison with Experimental Results}

In order to investigate the adequacy of the model presented here samples of austenitic stainless steel were tested in constant load test and slow strain rate test, and the experimental results were checked with the model. The model parameters identified experimentally for this alloy are given by:

$\mathrm{E}=193.000[\mathrm{MPa}] ; \mathrm{K}=95.336[\mathrm{MPa} \mathrm{s}], \mathrm{N}=165 ; \mathrm{a}=52 ; \quad \eta=$ $0.013[\mathrm{MPa} / \mathrm{h}]$. Based on experimental observations, it was adopted the following critical value for the damage: $\mathrm{D}_{\mathrm{cr}}=0.13$.

$$
\mathrm{S}[\mathrm{MPa} / \mathrm{h}]=\left\{\begin{array}{lll}
2.11 \times 10^{-3} & \text { for } \mathrm{pH}=0.00 \\
7.36 \times 10^{-4} & \text { for } \mathrm{pH}=0.50 \\
0 & \text { for } & \text { air }
\end{array}\right.
$$




$$
\mathrm{R}=\left\{\begin{array}{lll}
35.0 & \text { for } & \mathrm{pH}=0.00 \\
6.0 & \text { for } & \mathrm{pH}=0.50 \\
0 & \text { for } & \text { air }
\end{array}\right.
$$

\section{Constant Load Tests}

In this section, the results of constant load (CL) tests performed in different environments are compared with the model predictions. For the CL tests, Eq. (1) was rewritten as $\varepsilon(\mathrm{t})$ then the curves were calculated using Eq. (2), (3), (4) and the next equation

$$
\varepsilon=\frac{\sigma}{(1-\mathrm{D}) \mathrm{E}}+\varepsilon_{\mathrm{p}}
$$

The ordinary differential Eq. (3) and (4) were solved using embedded $4^{\text {th }}$ order Runge-Kutta method with $5^{\text {th }}$ order error estimate (Cash and Karp, 1990). The variable order Runge-Kutta method is a family of explicit Runge-Kutta formulas. Each member of the family consists of a fifth-order formula that includes embedded formulas of orders from 1 to 4 . A proper order formula is chosen by calculating the solution at several different orders before the full Runge-Kutta step is computed. The algorithm is fully described by Cash and Karp (1990).

Figure 2 shows the theoretical and experimental corrosion elongation curves at a constant initial stress $\left(\sigma_{0}=375 \mathrm{MPa}\right)$ obtained in the air, and in an aerated solution prepared from $1 \mathrm{M}$ $\mathrm{NaCl}$ acidified with $1 \mathrm{M} \mathrm{HCl}$ to adjust the desired $\mathrm{pH}$ to 1.00 and 0.50 . The model prediction is in very good agreement with the experimental results.

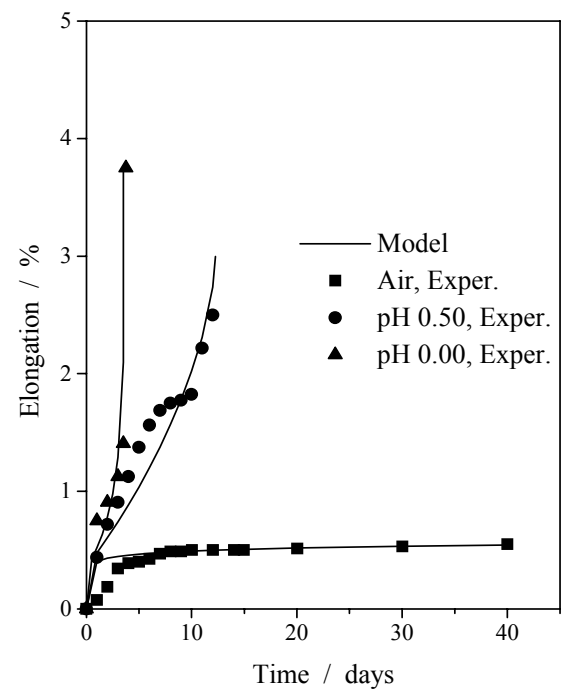

Figure 2. Elongation curves in different environments with initial.

$$
\sigma=375 \mathrm{MPa} .
$$

Table 2 shows the fracture time obtained experimentally for different $\mathrm{pH}^{\prime}$ s and the theoretical value $\mathrm{t}_{\mathrm{r}}$ obtained from solution of Eq. (13).

Table 2. Experimental and theoretical fracture time.

\begin{tabular}{|l|l|l|}
\hline & Experimental $\left(\mathrm{t}_{\mathrm{r}}\right)$ & Model $\left(\mathrm{t}_{\mathrm{r}}\right)$ \\
\hline $\mathrm{pH}=0.50$ & $372 \mathrm{~h}$ & $372 \mathrm{~h}$ \\
\hline $\mathrm{pH}=0.00$ & $90.28 \mathrm{~h}$ & $90 \mathrm{~h}$ \\
\hline
\end{tabular}

Figure 3 shows the theoretical $\sigma_{0} \times \log \left(t_{\mathrm{r}}\right)$ curve. The behavior is almost linear, which is in agreement with experimental observations (Nishimura et al., 2003) for austenitic stainless steel in acid environments at room temperature.

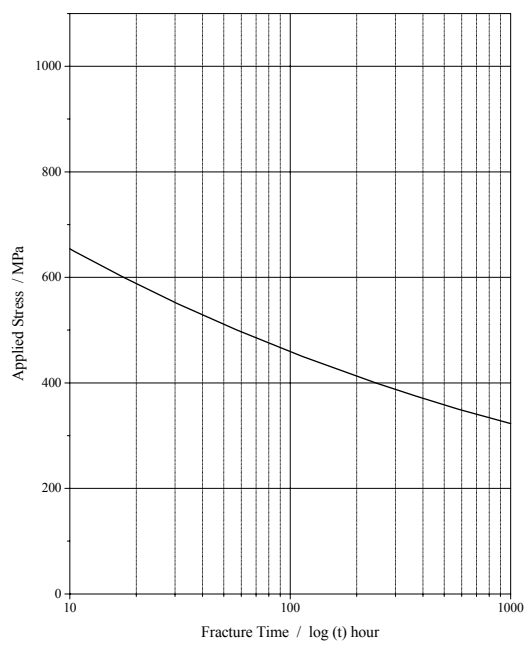

Figure 3. Model prevision of relative stress corrosion cracking resistance.

\section{Slow Strain Rate Tests}

In this section, the experimental stress-strain curves obtained in slow strain rate tests performed in different environments are compared with the model previsions. Figure 4 shows the theoretical and experimental stress-strain curves with $\dot{\varepsilon}=3 \times 10^{-6} \quad\left[\mathrm{~s}^{-1}\right]$ obtained in the air and in an aerated solution prepared from $1 \mathrm{M}$ sodium chloride acidified with $1 \mathrm{M}$ chloride acid to adjust the $\mathrm{pH}$ to 1.00 and 0.50 . In SSR test the elongation is given by Eq. (18). The model prediction also matched with the experimental results.

$$
\varepsilon=\dot{\varepsilon} t
$$

In this case, the $\sigma(\mathrm{t})$ curves were calculated using Eq. (1), (2), (3) and (4). The ordinary differential equations, Eq. (3) and (4) were solved using the same Runge-Kutta algorithm used in CL test simulations.

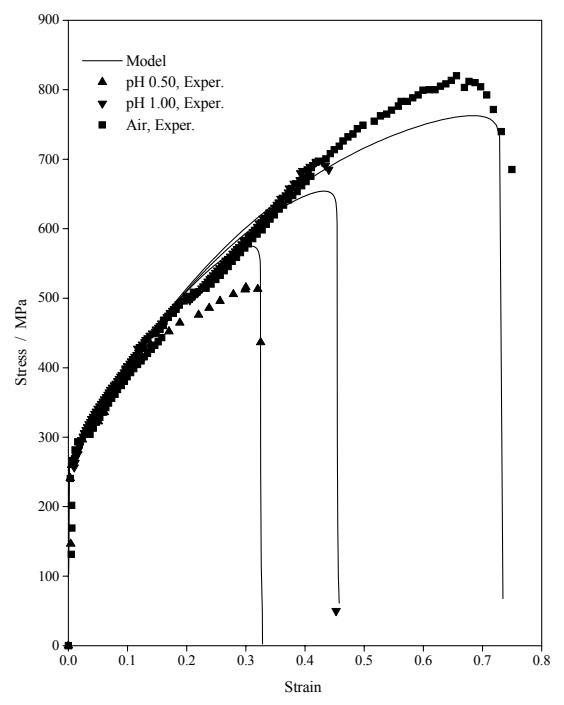

Figure 4. Stress-strain curves for different $\mathrm{pH}$ 's, $\dot{\varepsilon}=3 \times 10^{-6} \mathrm{~s}-1$. 
Figure 5 shows the damage evolution computed for the SSR tests performed in the air and in a solution with $\mathrm{pH}=0.50$. From this calculation it is possible to observe that the corrosive environment strongly affects the damage evolution. This parameter shows explicitly the evolution of damage due to stress corrosion during the testing.

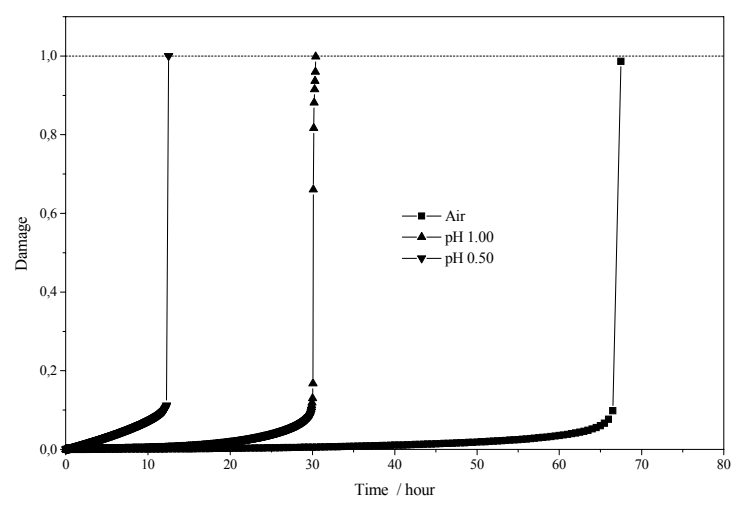

Figure 5. Damage evolution for different environments.

The damage variable presents a stable evolution until a critical experimental value of $\mathrm{D}_{\mathrm{cr}} \approx 0.13$ is reached. Afterwards the damage increases abruptly until the limit value $\mathrm{D}=1$ corresponding to the fracture. At this final stage, the plastic damage is responsible for the abrupt increase of the damage rate.

Although there is a good agreement between the model prediction and the experiments in constant load tests, in the case of slow strain rate tests the results present a discrepancy for small values of $\mathrm{pH}$, as shown in figure 6 . Such limitation of the model in the environment with $\mathrm{pH}=0.00$ may be explained through the more uniform distribution of the cracks induced by SCC, which may modify the damage and subsequently the mechanical behavior.

In environments with higher values of $\mathrm{pH}$, the metal is virtually unattacked over most of the surface, while fine cracks progress through it. Nevertheless, in a typical SSR test with $\mathrm{pH}=0.00$, about 60 cracks were found for a gauge length of $16[\mathrm{~mm}]$ besides an intense uniform corrosion.

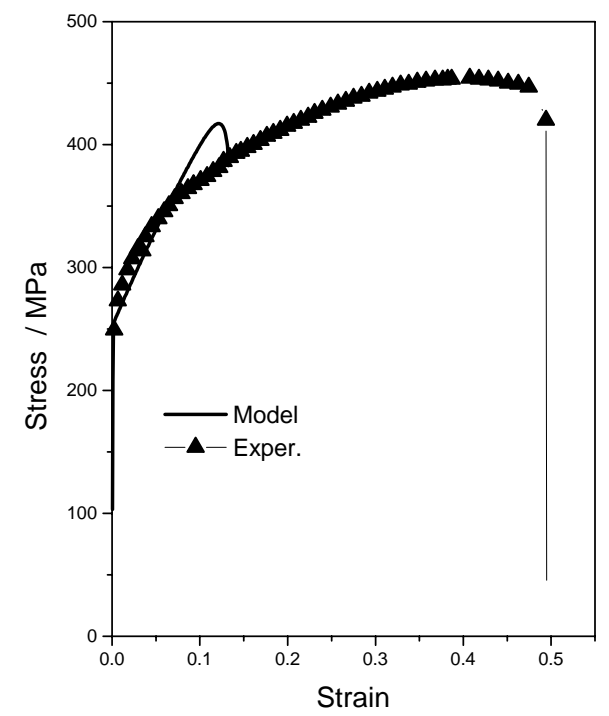

Figure 6. Stress-strain curve, $\mathrm{pH}=0.00, \dot{\varepsilon}=3 \times 10^{-6} \mathrm{~s}-1$.
Such a great density of cracks requires a gradient enhanced damage theory as proposed by Chimisso (1994). In this theory, an evolution law with an additional term must be used

$$
\frac{\partial \mathrm{D}}{\partial \mathrm{t}}=\frac{\eta \sigma^{2}}{\mathrm{E}(1-\mathrm{D})^{\mathrm{a}}} \dot{\varepsilon}_{\mathrm{p}}+\left(\frac{\mathrm{S} \sigma}{(1-\mathrm{D})}\right)^{\mathrm{R}}+\underbrace{\mathrm{C} \frac{\partial^{2} \mathrm{D}}{\partial \mathrm{z}^{2}}}_{\text {additional term }}
$$

where $\mathrm{Z}$ is the axial coordinate and $\mathrm{C}$ a material parameter. The smaller is $\mathrm{C}$, the most localized is the damage. However, the earlier proposed evolution law is suitable to model the majority of experimental results presented here, regardless the specific micromechanism that takes place in the interface metal-electrolyte.

\section{Sensitivity Analysis}

Sensitivity analysis is a commonly methodology of studying the effect of parameter variations on the behavior of mathematical models in various branches of mechanical field. This procedure used in conjunction with traditional digital simulations resulting in an added insight into behavior of models. An important requirement in parameter estimation is that the sensitivity coefficients should not be of small magnitude, and when two or more parameters are estimated simultaneously, their sensitivity coefficients must be linearly independent over the experimental time domain (Beck et al., 1985).

In the present work, we analyzed the scaled sensitivity coefficients, which are defined as

$$
\mathrm{X}_{\mathrm{s}}(\mathrm{t})=\beta_{\mathrm{s}} \frac{\partial \varepsilon(\mathrm{t})}{\partial \beta_{\mathrm{s}}}, \mathrm{s}=1,2, \ldots, 6
$$

to analyze CL test and

$$
X_{s}(t)=\beta_{s} \frac{\partial \sigma(t)}{\partial \beta_{s}}, s=1,2, \ldots, 6
$$

to study SSR test. In both equations, $\beta$ are the parameters used in the present sensitivity analysis and may be one of these six parameters: $\left\{\mathrm{S}, \mathrm{R}, \mathrm{K}, \mathrm{N}, \mathrm{v}_{1}, \mathrm{v}_{2}\right\}$. As it can be observed in Eq. (20) and (21), the scaled sensitivity coefficients have all the same units of $\varepsilon$ (in $C L$ test) or $\sigma$ (in SSR test). The sensitivity coefficients were calculated using a numerical approximation. Therefore, Eq. (20) was calculated as

$$
\begin{aligned}
\frac{\partial \varepsilon(\mathrm{t})}{\partial \beta_{\mathrm{s}}} & =\frac{\varepsilon\left(\beta_{1}, \cdots, \beta_{\mathrm{s}}+\Delta \beta_{\mathrm{s}}, \cdots, \beta_{6}\right)-\varepsilon\left(\beta_{1}, \cdots, \beta_{\mathrm{s}}-\Delta \beta_{\mathrm{s}}, \cdots, \beta_{6}\right)}{2 \Delta \beta_{\mathrm{s}}} \\
\text { with } \mathrm{s} & =1,2, \ldots, 6
\end{aligned}
$$

and Eq. (21) as

$$
\begin{aligned}
\frac{\partial \sigma(\mathrm{t})}{\partial \beta_{\mathrm{s}}} & =\frac{\sigma\left(\beta_{1}, \cdots, \beta_{\mathrm{s}}+\Delta \beta_{\mathrm{s}}, \cdots, \beta_{6}\right)-\sigma\left(\beta_{1}, \cdots, \beta_{\mathrm{s}}-\Delta \beta_{\mathrm{s}}, \cdots, \beta_{6}\right)}{2 \Delta \beta_{\mathrm{s}}} \\
\text { with } \mathrm{s} & =1,2, \ldots, 6
\end{aligned}
$$

Similar shapes (time dependence) of sensitivity coefficients for two different parameters indicate that their effects on the model response are similar. Therefore it may not be possible to split them up. Larger sensitivity coefficients are related to better chances of obtaining good estimates. As it may be seen in figure $7, v_{1}$ and $v_{2}$ are linearly dependent and, indeed, have larger effects on model. $\mathrm{R}$ and $\mathrm{S}$ have largest magnitude at the near the end of the test, and such behavior is clearer in SSR simulation, as depicted in figure 8 . However, at the end of test there is a lack of reliability of prediction, 
due to heterogeneous processes like corrosion and deformation phenomena.

This sort of analysis is important to demonstrate which parameters are really important in each model. Consequently it may help identify the set of parameters that should be measured or determined very carefully.

In this sense, the figure 7 shows the sensitivity curves based on Eq. (22). It is clear that the parameter $\mathrm{N}$ has little importance in the model. Otherwise, $\mathrm{S}$ and $\mathrm{R}$ values are very important in this model and their values should be determined with awareness. Figure 8 shows the sensitivity curves based on Eq. (23). As shown before, the parameter $\mathrm{N}$ is not important in the model. But $\mathrm{v}_{1}$ and $\mathrm{v}_{2}$ are very important for $0.04 \leq \varepsilon \leq 0.11$ and $\mathrm{K}$ is important for $\varepsilon \leq 0.08$ and $\mathrm{S}$ and $\mathrm{R}$ values are important for $\varepsilon>0.08$.

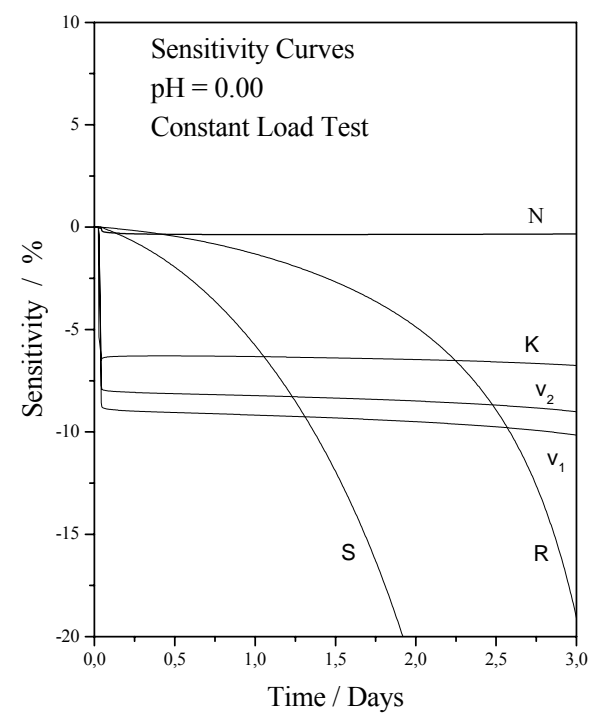

Figure 7. Sensitivity coefficients for $\varepsilon \%$.

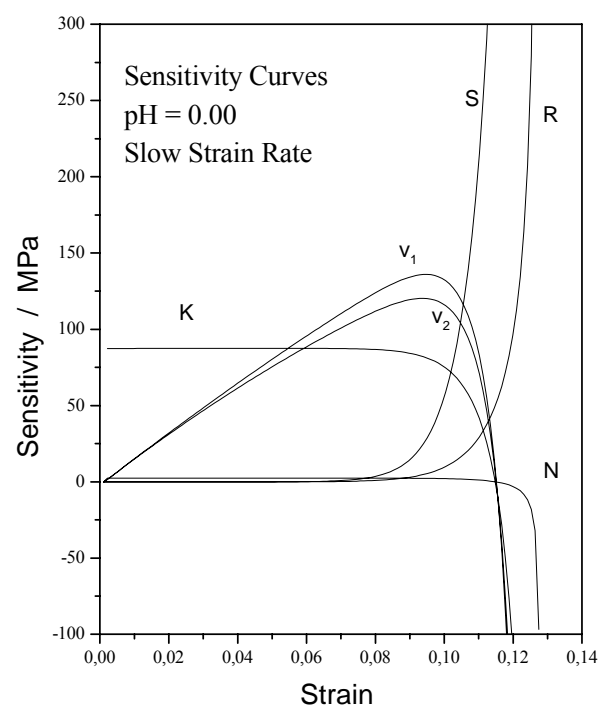

Figure 8. Sensitivity coefficients for $\sigma(\mathrm{MPa})$.

\section{Conclusions}

The present paper is a step towards the modeling of stress corrosion cracking phenomenon in metallic materials by using
Continuum Damage Mechanics. A simple continuum damage model is proposed to describe SSR and CL tests in austenitic stainless steels. The model predictions are in good agreement with experiments where the alloy/environments system is AISI 304 austenitic stainless steel/acid chloride solutions. The results obtained by experiment and predicted parameters time of fracture and total elongation are practically identical. The agreement between theory and experiment is very good in tests performed in air or in environments with $\mathrm{pH}$ value equal or greater than 0.50 . For $\mathrm{pH}=0.00$, due to the more uniform distribution of corrosion cracks and simultaneous uniform corrosion, the simulation of a slow strain rate test underestimated the elongation of the specimen at the rupture. Using an alternative approach based on gradient enhanced theory may probably surpass such limitation of the model. The effective development of corrosion damage models match with experimental results. Moreover, it successfully model the actual damage during the usual constant load and slow strain rate tests.

\section{Acknowledgements}

The authors wish to acknowledge the financial support provide by FAPERJ, CNPq, UFF and UERJ.

\section{References}

Bastos, I. N., Nogueira, R. P. and Gomes, J. A. P., 2005, "Electrochemical Impedance and Current Fluctuation Analysis During Slow Strain Rate Test of a UNS S30400 Stainless Steel in Low pH Media”, J. Braz. Chem. Soc., Accepted 2005, available: http://jbcs.sbq.org.br.

Bastos, I.N., 1999, "Stress Corrosion Cracking of Stainless Steel in Acidic Media", (In Portuguese), Ph.D. Thesis, PEMM/COPPE/UFRJ, Rio de Janeiro, Brazil, 232p.

Bastos, I.N., Gomes, J. A. C. and Costa-Mattos, H. S., 1998, "Modeling of Slow Strain Rate Corrosion testing of Austenitic Stainless Steel by Continuum Damage Mechanics", 1998, Proceedings of EUROCORR'98, Utrecht, The Netherlands, pp.116.

Beck, J. V., Blackwell, B. and St. Clair Jr., C. R., 1985, "Inverse Heat Conduction", John Wiley \& Sons, New York.

Cash, J. R. and Karp, A. H., 1990, "A Variable Order Runge-Kutta Method for Initial Value Problems with Rapidly Varying Right-Hand Sides", ACM Trans. Math. Software, Vol.16, pp. 201-222.

Chimisso, F. E. G., 1994, "A Continuum Damage Model for Materials with Elasto-Plastic Behavior", (In Portuguese), Ph.D. Thesis, DEM/PUCRio, Rio de Janeiro, Brazil, 130p.

Garud, Y. S., 1990, “An Incremental Damage Formulation for the Stress Corrosion Cracking and Its Application to Crack Growth Interpretation Based on CERT Data", Corrosion, Vol.46, N.12, pp.968-674.

Kachanov, L. M., 1986, "Introduction to Damage Mechanics", Kluwer Academic Publishers, Dordrecht, The Netherlands, 135p.

Lemaitre, J. and Chaboche, J. L., 1990, "Mechanics of Solid Materials", Cambridge University Press.

Newman, R. C., 1995 "Stress-Corrosion Mechanisms, In: Corrosion Mechanisms in Theory and Practice", Marcel Dekker Inc. New York.

Nishimura, R. and Maeda, Y., 2004, "SCC Evaluation of Type 304 and 316 Astenitic Stainless Steels in Acidic Chloride Solutions Using the Slow Strain Rate Technique”, Corrosion Science, Vol.46, pp.769-785.

Nishimura, R. and Maeda, Y., 2003, "Stress Corrosion Cracking Susceptibility of Sensitized Type 316 Stainless Steel in Hydrochloric Acid Solution - Effect of Sensitizing Time", Corrosion Science, Vol. 45, pp.18471862.

Nishimura, R. C., Sulaiman, A. and Maeda, Y., 2003, "Stress Corrosion Cracking Susceptibility of Sensitized Type 316 Stainless Steel in Sulphuric Acid Solution", Corrosion Science, Vol.45, pp.465-484.

Santarini, G., 1989, "Comprehensive Interpretation of CERTS: A Method for the Characterization and the Prediction of IGSCC", Corrosion, Vol.45, N.5, pp.369-381.

Vera Jr., J. R. H., 2002, "Simulation of Stress Corrosion Cracking of Metallic Bars under Inelastic Deformation", (In Portuguese), M.Sc. Dissertation, PGMEC/UFF, Niterói, Brazil, 90p. 